\section{Tratamento Medicamentoso dos Tumores Hipofisários. Parte II: Adenomas Secretores de ACTH, TSH e Adenomas Clinicamente Não-Funcionantes}

\section{RESUMO}

Este artigo revisa o potencial papel do tratamento medicamentoso para os adenomas hipofisários secretores de $\mathrm{ACTH}, \mathrm{TSH}$ e aqueles clinicamente não-funcionantes (ACNF). Metirapona, mitotano e cetoconazol (preferivel por causar menos efeitos colaterais) são as drogas mais eficazes no controle do hipercortisolismo, mas nenhuma delas supera a eficácia da cirurgia transesfenoidal (TSA). O tratamento medicamentoso da doença de Cushing está, portanto, melhor indicado para pacientes aguardando o efeito pleno da radioterapia ou, como alternativa para esta última, em casos de hipercortisolismo persistente após TSA, e para pacientes com rejeição ou limitações clínicas para a cirurgia. Outra indicação potencial seria em idosos com microadenomas ou pequenos macroadenomas, ou em casos associados a sela vazia. No que se refere aos adenomas secretores de TSH, os análogos somatostatínicos (SRIFa) proporcionam normalização dos hormônios tiroideanos em até $95 \%$ dos casos. Assim, eles podem se mostrar úteis em casos de insucesso da cirurgia ou como terapia primária de casos selecionados. Ocasionalmente, agonistas dopaminérgicos (DA), sobretudo a cabergolina, também podem ser eficazes. Em contraste, DA e SRIFa raramente induzem uma significante redução das dimensões dos ACNFs. Por isso, em pacientes com tais tumores, essas drogas devem ser principalmente consideradas diante de contra-indicações ou limitações clínicas para a cirurgia ou quando a cirurgia e a radioterapia tenham sido mal-sucedidas. (Arq Bras Endocrinol Metab 2000;44/6: 455-470)

Unitermos: Adenomas hipofisários; Doença de Cushing; Tratamento; Inibidores da esteroidogênese adrenal; Análogos da somatostatina; Agonistas dopaminérgicos.

\begin{abstract}
This article reviews the potencial role of medical treatment for both $\mathrm{ACTH}$ and TSH secreting pituitary adenomas, as well as for clinically non-functionning pituitary adenomas (CNFPA). Metyrapone, mitotane and ketoconazole (preferable for causing less side-effects) are the most effective drugs for the control of hypercortisolism but none of them surpasses the efficacy of transsphenoidal surgery (TSA). Drug therapy in Cushing's disease is therefore better indicated for patients waiting for the full effect of radiotherapy or, as an alternative to radiotherapy, for cases of TSA failure as well as patients that refuse or have clinical limitations to surgery. Other potential indications for medical treatment in Cushing's disease include elderly patients with microadenomas or small macroadenomas, as well as cases associated to an empty sella. Concerning TSH-secreting adenomas, somatostatin analogues (SRIFa) lead to normalization of thyroid hormones in up to $95 \%$ of treated patients. Therefore they may represent an useful tool for long-term treatment of such rare tumors in case of surgery failure or as primary therapy for selected cases. Occasionaly, dopamine agonists (DA), especially cabergoline, may also be efficacious in normalizing hormone levels. In contrast. DA and SRIFa rarely induce significant tumor shrinkage in patients with CNFPA. Thus, these drugs should be con-
\end{abstract}

revisão

\author{
Lucio Vilar \\ Luciana Naves \\ Maria da C. Freitas \\ Sebastião Oliveira Jr. \\ Verônica Leite \\ Viviane Canadas
}

Disciplina de Endocrinologia da Universidade Federal de Pernambuco (LV, VL, VC), Disciplina de Endocrinologia da Universidade de Brasilia (LN), Unidade de Endocrinologia do Hospital Getúlio Vargas (MCF) e Disciplina de Endocrinologia da Universidade de Pernambuco (SOJr)

Recebido em: 21/05/99 Revisado em: 13/01/00 e 24/10/00 Aceito em: $28 / 10 / 00$ 
sidered particularly for patients who are poor candidates for surgery or in whom surgery and radiotherapy have failed to control the disease. (Arq Bras Endocrinol Metab 2000;44/6: 455-470)

Keywords: Pituitary Adenomas; Cushing's disease: Treatment; Inhibitors of adrenal steroidogenesis; Somatostatin analogues; Dopamine agonists.

$\mathbf{N}$ ESTA REVISÃo, é aVAliada a eFicácia da abordagem farmacológica para os adenomas hipofisários secretores de ACTH, TSH e os adenomas clinicamente não funcionantes, comparando-a aos resultados obtidos com a cirurgia e/ou radioterapia, com comentários sobre sua relevância no tratamento desses tumores.

\section{ADENOMAS SECRETORES DE ACTH}

Os adenomas secretores de ACTH são a causa da doença de Cushing, que representa 70 a $80 \%$ dos casos de síndrome de Cushing (1). A grande maioria (90\%) desses tumores é constituída de microadenomas $(<\mathrm{lcm})$ e tradicionalmente têm como tratamento de escolha sua retirada cirúrgica por via transesfenoidal (1-3). Outras opções são a radioterapia hipofisária, a adrenalectomia bilateral e drogas que reduzem a cortisolemia ou antagonizam os efeitos periféricos do cortisol $(1,2)$.

\section{Cirurgia}

Quando realizada por neurocirurgiões experientes em doença de Cushing, a adenomectomia transesfenoidal (TSA) possibilita a cura de 83 a $91 \%$ dos pacientes com microadenomas $(4,5)$ e de 25 a $73 \%$ daqueles com macroadenomas $(2,4-7)$. Em dois serviços brasileiros, o percentual geral de cura cirúrgica variou de $50 \%$ a $86 \%(8,9)$. Entre 610 pacientes submetidos a TSA, recidiva do hipercortisolismo aconteceu em $7 \%$ dos casos considerados curados (10). No caso de macroadenomas, essa recidiva tende a ser mais precoce e mais freqüente, chegando em alguns estudos a $36 \%$ (6). Nos casos curados pela cirurgia, a reposição de glicocorticóides se faz necessária até a recuperação do eixo hipotálamo-hipófise-adrenal, o que pode levar até 12 meses ou mais para acontecer $(2,11)$.

\section{Radioterapia}

Como tratamento primário da doença de Cushing, a radioterapia convencional, na dose de 4000-5000 cGy (20-25 sessões) permitiu a normalização da secreção diária do cortisól em apenas 17 de 72 pacientes $(23,6 \%)$ (10-12). Além disso, podem ser necessários até 2 anos ou mais para que se obtenha um efeito terapêutico pleno
(5,13-16). Um outro importante inconveniente da radioterapia é o frequente surgimento de hipopituitarismo $(1,2)$. Entre 139 pacientes com doença de Cushing, observaram-se as seguintes deficiências hormonais: $\mathrm{GH}$ em $86 \%$, ACTH em 20\%, LH/FSH em 18\% e TSH em $6 \%$ (13-16). A principal indicação da radioterapia é para pacientes com hipercortisolismo persistente ou recidivante após a TSA $(2,5)$; nesses casos, consegue-se uma taxa de remissão de 55 a $83 \%$, geralmente dentro dos primeiros dois anos após a radioterapia $(17,18)$. A irradiação hipofisária curou também $80 \%$ de um grupo de 15 crianças, sendo freqüentemente considerada o tratamento de escolha nessa faixa etária $(7,10,19)$. Mostra-se também útil na prevenção da síndrome de Nelson em pacientes submetidos a adrenalectomia bilateral (20).

Os dados disponíveis com a radiocirurgia gamma-knife na doença de Cushing são ainda limitados (21). Em um serviço escandinavo, foram observados os seguintes percentuais de cura: $41 \%$ após $1-2$ anos, $76 \%$ após $2-5$ anos e $76 \%$ após 5-10 anos (22). Outros autores relataram normalização do cortisol livre urinário em $50 \%$ dos pacientes, 13 meses após a radiocirurgia (2l). Hipopituitarismo também é bastante comum após a radiocirurgia gamma-knife, tendo sido relatado em cerca de $50 \%$ dos pacientes $(5,22)$.

\section{Adrenalectomia Bilateral}

Antes do advento da cirurgia transesfenoidal, a adrenalectomia bilateral era considerada o tratamento de escolha para a doença de Cushing. Nas mãos de um cirurgião experiente, ela potencialmente cura $100 \%$ dos casos. No entanto, implica necessidade de reposição permanente de glicocorticóide e mineralocorticóide, morbidade e mortalidade pós-operatórias potencialmente elevadas, além do considerável risco para o surgimento da síndrome de Nelson $(2,20,23)$. Esta última se caracteriza pelo surgimento de um tumor hipofisário localmente agressivo, que secreta níveis elevados de $\mathrm{ACTH}$, resultando em hiperpigmentação $(2,22,23)$. A adrenalectomia bilateral deve ser considerada nos casos de doença de Cushing persistente ou recidivante após cirurgia transesfenoidal e/ou radioterapia, ou para pacientes com síndrome de Cushing ACTH-dependente, sem etiologia definida, que se apresentem com uma evolução muito agressiva (p.ex., hipertensão ou diabetes mellitus incontroláveis, osteoporose grave com múltiplas fraturas vertebrais, etc.) (2).

\section{Tratamento Medicamentoso}

As principais drogas disponíveis para o tratamento da doença de Cushing estão listadas na tabela 1 . Elas podem atuar por mecanismos diversos, seja inibindo a 


\section{Tabela 1.Tratamento medicamentoso da Doença de Cushing}

- Drogas inibidoras da esteroidogênese adrenal

- Cetoconazol (Nizoral $B$, Candoral $B$, etC.)

- Metirapona*

- Aminoglutetimida (Orimeten $\mathbb{B}$ )

- Etomidato (Hypnomidate (B))

- Mitotano (Lisodren)

- Trilostano*

- Drogas neuromoduladoras da secreção do ACTH

- Bromocriptina (Parlodel $(B$, Bagren $(B)$

- Ciproeptadina (Periatin $®$ )

- Ritanserina*

- Valproato sódico*

- Drogas antagonistas dos receptores dos glicocorticóides - Mifepristone*

* Não comercializados no Brasil

esteroidogênese adrenal, seja inibindo a secreção de ACTH ou, perifericamente, competindo com os receptores de glicocorticóides. A medicação mais utilizada no nosso meio é o cetoconazol (2).

O tratamento medicamentoso na doença de Cushing está geralmente indicado nas seguintes situações: a) no pré-operatório da TSA e da adrenalectomia, para diminuir a morbimortalidade decorrente das complicaçōes do hipercortisolismo (diabetes mellitus, hipertensão, hipocalemia, maior susceptibilidade a infeç̧ões, etc.) $(1,2,10) ; b)$ em pacientes submetidos à radioterapia hipofisária, enquanto se aguarda seu efeito terapêutico pleno $(1,2,10)$. Drogas são também de grande utilidade em casos de síndrome de Cushing ACTH-dependente, de leve ou moderada intensidade, em que a avaliação laboratorial e por imagem não permitiu uma definição etiológica $(2,10)$. Esses pacientes podem ser mantidos com a medicação redutora da cortisolemia e reavaliados periodicamente (2).

\section{I) Drogas Inibidoras da Esteroidogênese Adrenal}

Atuam em várias etapas da esteroidogênese, bloqueando as reações catalizadas pelo citocromo $\mathrm{P}_{450}$ (figura 1).

1. Cetoconazol. Este derivado imidazólico é um potente inibidor da esteroidogênese adrenal e gonadal (24). O principal efeito é sobre a enzima 17,20-liase, mas ele também inibe a ação da $11 \beta$-hidroxilase, $17 \alpha$ hidroxilase, 18-hidroxilase e a colesterol-desmolase $(24,25)$. Parece também reduzir a liberação do ACTH (basal e estimulada pelo $\mathrm{CRH}$ ), através de um efeito direto sobre a subunidade catalítica da adenilciclase dos corticotrofos (26). Pode ainda competir com o cortisol nos receptores para glicocorticóides (17).

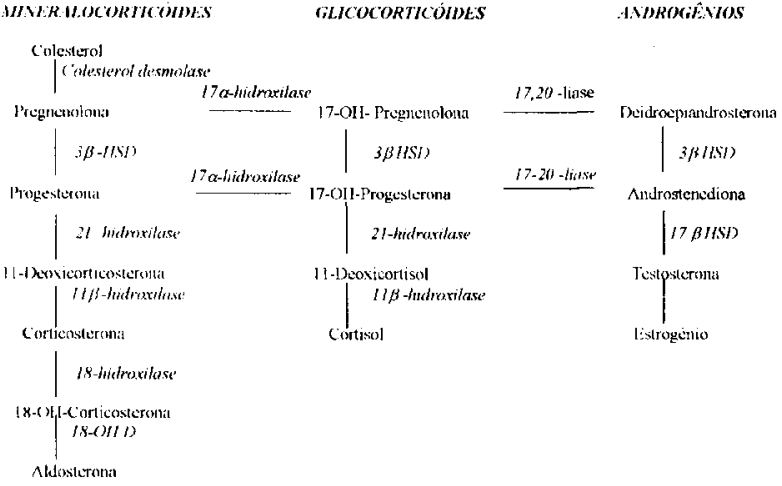

Figura 1. Principais etapas da esteroidogênese adrenal ( $3 \beta$ $H S D=3$ beta-hidroxiesteróide desidrogenase $; 18-O H D=18$ hidroxidesidrogenase)

Doses entre 200 e $1.200 \mathrm{mg} /$ dia são necessárias para controle do hipercortisolismo (24). Entretanto, na maioria dos pacientes a resposta terapêutica foi observada com doses de $600-800 \mathrm{mg} / \mathrm{dia}$, administrados em duas a três tomadas (10). Recomenda-se iniciar o tratamento com $200 \mathrm{mg}$ duas vezes ao dia para testar a tolerabilidade do paciente (27). A dose deve ser reajustada a cada uma ou duas semanas até que o cortisol livre urinário (UFC) caia para os níveis superiores da normalidade (2). Manter o UFC nesse patamar deve ser a meta do tratamento, com a finalidade de se minimizar o risco de insuficiência adrenal (27).

Eficácia clínica. O uso do cetoconazol permite uma rápida resposta clínica sobre as alterações cushingóides clássicas, bem como reversão ou melhora importante da hiperglicemia, hipocalemia e/ou hipertensão $(28,29)$. Em 12 séries, totalizando 85 pacientes com doença de Cushing, a terapia com cetoconazol por até 7,5 meses, na dosagem de 400-1.200 $\mathrm{mg} /$ dia, permitiu um percentual médio de $81 \%$ no controle do hipercortisolismo, com melhora do mesmo em outros $11 \%(10)$. Em dois estudos mais recentes, o cetoconazol mostrou-se eficaz como terapia única em três idosos com doença de Cushing (30) e em uma paciente com imagem de sela vazia à ressonância magnética (31). Da mesma forma, Moncet e cols (32) observaram normalização do UFC em $82,5 \%$ de 41 pacientes com síndrome de Cushing (dos quais 33 tinham doença de Cushing). Cetoconazol já foi usado em algumas gestantes $\mathrm{com}$ doença de $\mathrm{Cu}^{-}$ shing, tendo se mostrado seguro e eficaz (34). Na presença de níveis muito elevados de UFC, pode se fazer necessária a associação do cetoconazol com metirapona ou aminoglutetimida (27).

Temos usado o cetoconazol principalmente em pacientes com hipercortisolismo persistente após a cirur- 
gia e/ou radioterapia, bem como no pré-operatório de TSA ou adrenalectomia, conseguindo redução ou normalização do UFC em aproximadamente $80 \%$ dos pacientes, na dose de $400-1.200 \mathrm{mg} / \mathrm{dia}$. Uma de nossas pacientes, que recusou a cirurgia e a radioterapia, vem se mantendo adequadamente controlada há 15 meses $(600 \mathrm{mg} / \mathrm{dia})$. Escape do bloqueio enzimático adrenal, com recidiva do hipercortisolismo, já foi relatado $(32,33)$, mas parece ser incomum $(10)$, particularmente em pacientes previamente submetidos à cirurgia ou radioterapia (28). Em um caso notável, o cetoconazol vinha mantendo uma paciente em remissão clínica $\mathrm{e}$ bioquímica há 7 anos (31).

Efeitos colaterais. O cetoconazol geralmente é bem tolerado. Em 4 estudos, envolvendo 52 pacientes, observou-sc clevação das transaminases em 15\%, ginecomastia em $13 \%$, distúrbios gastrointestinais em $8 \%$, edema em $6 \%$ e erupção cutânea em $2 \%$ (10). Estas reaçōes adversas não são dose-dependentes. Hepatotoxidade é o efeito colateral mais temido, porém, geralmente é leve e transitória $(2,32)$. Toxidade hepática sintomática é vista em apenas um em cada 15.000 indivíduos tratados (24). Excepcionalmente, insuficiência hepática fatal pode acontecer (24), mas a maioria dos óbitos ocorrera em situações em que o tratamento não foi interrompido, a despeito da disfunção hepática clinicamente evidente (10). A hepatite induzida pelo cetoconazol tipicamente se manifesta dentro de 60 dias após o início do tratamento (em um caso manifestou-se após 5 meses) e regride dentro de três meses da suspensão da medicação (24). Está recomendado, portanto, monitorizar a função hepática no início do tratamento e depois ocasionalmente. Hipoadrenalismo, geralmente reversível com a redução da dose, foi observado em $19 \%$ de um grupo de 68 pacientes com síndrome de Cushing (29), em $21 \%$ daqueles da série de Moncet e cols (32), mas em nenhum dos 34 casos tratados por Sonino e cols (28).

2. Metirapona. Atua principalmente sobre a enzima citocromo $\mathrm{P}_{450}$, responsável pela $\mathrm{l} l \beta$-hidroxilaçào, inibindo assim a conversão do 11 -desoxicortisol $\mathrm{cm}$ cortisol (24).

Eficácia clínica. Remissão do hipercortisolismo foi demonstrada em $50-75 \%$ dos pacientes com doença de Cushing apenas tratados com metirapona $(24,35)$ e em aproximadamente $85 \%$ daqueles também submetidos à radioterapia $(10,35)$. A longo prazo, escape durante o tratamento isolado foi observado em um estudo (10), mas não em outros dois $(35,36)$. Na literatura, há relato de casos mantidos por até 6 anos em uso de metirapona, sem efeitos colaterais importantes (28). Na nossa experiência, a metirapona também se mostrou com grande eficácia no preparo cirúrgico de pacientes com qualquer forma de síndrome de Cushing. Os níveis de cortisol caem dentro de 2 horas depois de iniciado o tratamento, mas como a metirapona tem uma ação de curta duração, é necessário administrá-la três vezes por dia. Recomenda-se iniciar o tratamento com $250 \mathrm{mg}$ três vezes ao dia (37) e monitorizar a resposta pela dosagem do cortisol plasmático em 5 momentos durante o dia, entre 9 e 21 horas (24). A titulação da dose é realizada $\mathrm{cm}$ intervalos de 72 horas, até que um nível de cortisol plasmático médio de $5,5 \mathrm{a} l 1 \mu \mathrm{g} / \mathrm{dl}$ seja atingido, o que equivale à taxa normal de produção de cortisol (24). A dose diária média para os pacientes com doença de Cushing e com síndrome de ACTH ectópico é, respectivamente, de $2 \mathrm{~g}$ e de $4 \mathrm{~g}$, em doses fracionadas $(2,24,37)$.

Os efeitos colaterais da metirapona são dosedependentes e significativamente mais comuns com doses maiores de $2 \mathrm{~g} /$ dia $(10,24)$. Entre as reações mais usuais temos erupção cutânea (que pode ser transitória) em 4\%, manifestações neurológicas (letargia, tonturas e ataxia) $\mathrm{em} 15 \%$, náuseas $\mathrm{em} 5 \%$ e edema $\mathrm{em}$ $8 \%$ (35). Insuficiência adrenocortical, devido à dose excessiva, é o principal risco da terapia com a metirapona, mas representa um problema raro sc o paciente for adequadamente monitorizado (24). Como a metirapona causa um aumento nos precursores esteróides androgênicos, tem como importante inconveniente o surgimento ou agravamento da acne e hirsutismo em mulheres $(10,24)$. Tal fato foi observado por Jeffcoat e cols (36) em $70 \%$ das pacientes tratadas durante seis ou mais meses. Esse efeito indescjávcl pode ser minimizado pela associação da droga com o cetoconazol, que tem açào antiandrogênica (24). Essa associação, contudo, pode resultar em elevação dos níveis pressóricos, por acúmulo de precursores da $11 \beta / 18$-hidroxilase (28). É importante salientar que o uso da metirapona propicia um rápido e grande aumento no nível de 11-desoxicortisol circulante que pode reagir de forma cruzada com alguns radioimunoensaios para cortisol, resultando em valores de cortisol elevados de forma espúria, sendo necessária cautela na interpretação dos valores do cortisol sérico c urinário livre $(2,10,24)$.

3. Aminoglutetimida. Esta droga anticonvulsivante é um outro potente inibidor da esteroidogênese adrenal; bloqueia a conversão do colesterol a pregnenolona e a $11 \beta / 18$-hidroxilação $(10,28)$. Em uma revisão, controle do hipercortisolismo somente foi observado em $46 \%$ dos pacientes (38). Outro fator limitante para o 
uso da aminoglutetimida é o conjunto de seus freqüentes efeitos colaterais: sonolência ( $30 \%)$, náuseas e anorexia (12\%), c erupção cutânea transitória (18\%) (38). Febre, hipotiroidismo e bócio podem também acontecer $(10,28)$.

4. Etomidato. Trata-se de um anestésico e derivado imidazólico que bloqueia a $11 \beta$-hidroxilação do deoxicortisol, permitindo a redução dos níveis plasmáticos do cortisol para os valores médios normais (10 $\mathrm{mg} / \mathrm{dL}$ ) dentro de 10 horas (7). Pode ser útil em situações de emergência, em doses sub-hipnóticas por via intravenosa $(0,3 \mathrm{mg} / \mathrm{kg} / \mathrm{h})$, quando a terapia por via oral não puder ser empregada (39).

5. Trilostano. Inibe a conversão da pregnenolona em progesterona (5). Em um estudo, redução do UFC não aconteceu em nenhum dos dois pacientes com doença de Cushing tratados (40).

6. Mitotano. Também conhecido como o,p'DDD, suprime a síntese do cortisol por inibição da $11 \beta$ hidroxilação e da clivagem da cadeia lateral do colesterol (colesterol desmolase), bem como por destruição de células do córtex adrenal $(24,41)$. Doses de até $4 \mathrm{~g}$ / dia são preferívcis por terem igual eficácia e melhor tolerabilidade de que doses maiores (24).

Eficácia clínica. Em pacientes com adenomas secretores de ACTH, o uso isolado do mitotano permitiu remissão do hipercortisolismo em torno de $80 \%$ dos casos, mas $\mathrm{em} 70 \%$ houve recorrência do distúrbio, 2 a 69 meses após a suspensão da droga (42). O tratamento combinado do mitotano com a irradiação hipofisária resultou em remissão bioquímica em aproximadamente $80 \%$ dos casos após 8 a 16 meses (43). Com a suspensão da droga, esse índice caiu para cerca de 50 a $60 \%$ (7). O efeito terapêutico pleno do mitotano requer até 6 semanas para ocorrer $(10,24)$. Além disso, o uso clínico da droga fica limitado por seus freqüentes efeitos colaterais, sendo mais comuns as manifestações gastrointestinais e neurológicas (10). Em um série de 36 casos, na dose de $0,5 \mathrm{a} 4 \mathrm{~g} /$ dia, as reaçōes adversas predominantes foram anorexia e náuseas ( $89 \%$ ), diminuição da memória (50\%) e ginecomastia (17\%) (43). Adicionalmente, podem surgir fraqueza geral, ataxia, remores, erupção cutânea, leucopenia e elevação da fosfatase alcalina, transaminases e colesterol (aumento de até $200 \%$ já foi descrito) $(10,24,43)$. A hipercolesterolemia se dá, sobretudo, às custas da fração LDL e responde às estatinas $(43,44)$. Hipocortisolismo é uma outra complicação freqüente do uso do mitotano, o que torna obrigatória a monitorização cuidadosa e periódica da função adrenal (7). Hipoaldosteronismo pode também surgir (10). Atualmente, o mitotano tem sido empregado quase exclusivamente como tratamento coadjuvante do carcinoma adrenocortical.

\section{II) Agentes Neuromoduladores da Secreção Hipofisária de ACTH}

\section{Bromocriptina.}

Eficácia clínica. Remissão do hipercortisolismo foi demonstrada em alguns casos de doença de $\mathrm{Cu}$ shing tratados com bromocriptina (BRC) $(10,45-50)$. Esta droga parece, no entanto, beneficiar apenas um limitado número de pacientes e, em dois estudos prospectivos, a prevalência de resposta à $\mathrm{BRC}$ variou de 4 a $23 \%(47,51)$. Na maioria das séries, a dose da BRC variou de 2,5 a $30 \mathrm{mg} /$ dia (10). Todavia, em alguns estudos, remissão do hipercortisolismo só foi evidenciada com $35 \mathrm{mg} / \mathrm{dia}$ ou mais (48-50). Crise addisoniana foi descrita em um caso de doença de Cushing tratado com BRC (10).

Outros agonistas dopaminérgicos, como a lisurida e a lergotrila, não se mostraram superiores a BCR no controle da hipersecreção do ACTH (28). Não há dados disponíveis sobre o uso isolado de cabergolina $(\mathrm{CAB})$ ou a quinagolida (52). Remissão do hipercortisolismo foi, contudo, relatada em uma paciente que recusou a cirurgia transesfenoidal e foi tratada com cetoconazol e CAB (52). Uma importante redução no ACTH plasmático, após uma única dose oral ou durante a terapia crônica com BCR, foi observada em alguns pacientes com a síndrome de Nelson (53), embora outros estudos não puderam demonstrar tal efeito (54). Recentemente, foi relatada remissão clínica e bioquímica completa em um caso de síndrome de Nelson, com desaparecimento do adenoma hipofisário, após um ano de tratamento com $\mathrm{CAB}$ (2 $\mathrm{mg} /$ semana) (55). A suspensão do tratamento foi seguida por nova elevação dos níveis de ACTH (55).

\section{Antagonistas Serotoninérgicos \\ 2.1. Ciproeptadina}

Eficácia clínica. Em uma revisão, observou-se que a terapia crônica com ciprocptadina (24-32 $\mathrm{mg} /$ dia) resultou em normalizaçào dos níveis plasmáticos do ACTH e cortisol em 30 a $50 \%$ dos pacientes $(2,56)$. Em um caso notável, uma jovem se mantinha adequadamente controlada com essa droga por ll anos, após insucesso da cirurgia hipofisária seguida de radioterapia (57). Ciproeptadina freqüentemente causa sonolência, hiperfagia e ganho de peso $(10,56)$. Crise addisoniana foi relatada em um paciente (10). 


\subsection{Ritanserina}

Eficácia clínica. A administração deste antipsicótico derivado da piperidina, na dose de 10-15 $\mathrm{mg} /$ dia, resultou em normalização do UFC em dois de três pacientes com doença de Cushing e sem adenoma hipofisário visível à ressonância magnética (28)

\section{Valproato de Sódio}

Eficácia clínica. Esta droga aumenta o ácido gama-aminobutírico (GABA) endógeno por inibir a GABA-aminotransferase (28). Parece inibir a secreção do ACTH através da inibição da liberação hipotalâmica do $\mathrm{CRH}$ (28). Na dose de 600-1.200 mg/dia, remissão clínica foi relatada em casos isolados de doença de Cushing $(51,58)$ e na síndrome de Nelson (58). Em um paciente, controle do hipercortisolismo foi conseguido pela combinação do valproato de sódio (1.200 mg/dia) com a BCR (15 mg/dia) (59).

\section{Octreotida}

Eficácia clínica. Consegue suprimir secreção do ACTH em alguns pacientes com tumores neuroendócrinos secretores de ACTH ou com a síndrome de Nelson, mas não naqueles com doença de Cushing $(10,28)$. O hipercortisolismo, ausente na síndrome de Nelson, induziria uma downregulation dos receptores somatostatínicos no adenoma hipofisário (28).

\section{III) Bloqueadores da Açāo Periférica dos Glicocorticóides}

Mifepristone ( $R U$ 486). Trata-se de um potente antagonista do receptor dos glicocorticóides cuja eficácia foi demonstrada em alguns pacientes com síndrome de Cushing $(7,24,28,60,61)$. Uma importante limitação para o uso do mifepristone é o fato dele não reduzir os níveis circulantes de cortisol (que podem aumentar), tornando difícil a monitorização da eficácia do tratamento, assim como a identificação de um eventual hipoadrenalismo (24). Sua principal indicação seria em situações de urgência, quando se pretende bloquear rapidamente a ação dos glicocorticóides sobre seu receptor (24). Por exemplo, rápida reversão das manifestações neuropsiquiátricas foi relatada em dois casos de psicose hipercortisolêmica (61). Como efeitos colaterais temos náuseas, vômitos, sinais de hipoadrenalismo e ginecomastia, após o uso prolongado (28).

\section{COMENTÁRIOS}

Entre as medicações disponíveis, os inibidores da esteroidogênese adrenal cetoconazol, metirapona e mitotano são os mais eficazes, permitindo controle do hipercortisolismo na maioria dos pacientes, mas sem superar a eficácia da cirurgia transesfenoidal (tabela 2 ). Por sua melhor tolerabilidade, cetoconazol desponta como a opção de escolha. O tratamento medicamentoso da doença de Cushing está indicado para pacientes aguardando o efeito pleno da radioterapia ou, como alternativa para esta última, para casos de hipercortisolismo persistente após a cirurgia transesfenoidal, bem como pacientes com rejeição ou limitações clínicas para a cirurgia. Deve também ser considerado para idosos com microadenomas ou pequenos macroadenomas, ou pacientes com sela vazia (figura 2). O eventual desenvolvimento de drogas mais eficazes na supressão da secreção de ACTH pelos corticotrofos, permitirá que um número significativa-

Tabela 2. Eficácia comparativa das diversas formas de tratamento para os adenomas secretores de ACTH (doença de Cushing)

\begin{tabular}{lll}
\hline & $\begin{array}{l}\text { Normalização da } \\
\text { secreção do } \\
\text { cortlsol (\%) }\end{array}$ & Referência \\
Drogas & $81-82,5$ & 10,32 \\
Cetoconazol & 80 & 42 \\
Mitotano & $50-75$ & 24,35 \\
Metirapona & 46 & 38 \\
Aminoglutetimida & $30-50$ & 5 \\
Ciproeptadina & $4-23$ & $10,47,51$ \\
Bromocriptina & 24 & $10-15$ \\
Radioterapia convencional & 21,22 \\
Radiocirurgia gamma-knife & $50-76$ & 4,5 \\
Cirurgia transesfenoidal & & $2,4-7$ \\
Microadenomas & $83-91$ & \\
Macroadenomas & $25-73$ & 2,4 \\
\hline
\end{tabular}

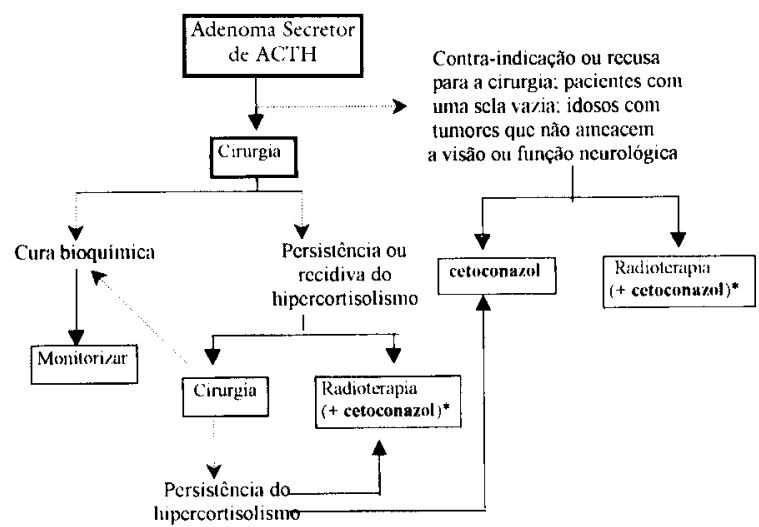

Figura 2. Algoritmo proposto para o manuseio dos adenomas secretores de ACTH.

* O cetoconazol deve ser mantido enquanto se aguarda o efeito pleno da radioterapia. A radiocirurgia gamma-knife é preferivel à radioterapia convencional, devido a sua aparente maior eficácia. 
mente maior de pacientes com a doença de Cushing possa ser tratado farmacologicamente.

\section{ADENOMAS SECRETORES DE TSH}

Os adenomas secretores de TSH, também chamados de tirotrofinomas (TSH-omas), são neoplasias raras, representando até $2,8 \%$ de todos os tumores hipofisários em grandes séries neurocirúrgicas e patológicas (62-65). Têm prevalência estimada de l:1.000.000 de pessoas, existindo até o momento cerca de 280 casos relatados na literatura, a maioria diagnosticada após o surgimento dos ensaios ultrassensiveis para o TSH (66).

Graus variados de hipertiroidismo, associados a sintomas de efeito de massa (cefaléia, distúrbios visuais, etc) são as manifestações mais habituais dos TSH-omas por ocasião do diagnóstico $(52,66)$. Laboratorialmente, os TSH-omas se caracterizam pela presença de níveis séricos aumentados de $\mathrm{T}_{3} \mathrm{e} / \mathrm{ou} \mathrm{T}_{4}(\mathrm{em}$ 95\% dos pacientes), associados a valores de TSH clevados (em 77\%) ou dentro do limite da normalidade (em 23\%), ausência de resposta do TSH ao TRH (em 75-80\%), falta de supressão do TSH pelo $\mathrm{T}_{3}(\mathrm{em} 80 \%)$ e níveis séricos elevados da subunidade- $\alpha$ (em 64\%). Em $81 \%$ dos casos, observa-se também uma relação molar subunidade- $\alpha /$ TSH maior que 1 (67-70). A hipersecreção do TSH pode vir associada à de outros hormônios, sobretudo GH e prolactina (66).

O principal diagnóstico diferencial é com a resistência hipofisária aos hormônios tiroideanos, uma vez que ambas as doenças cursam com hipertiroidismo central, mas requerem tratamentos distintos (66). A distinção entre as duas condiçōes pode ser dificil, especialmente se a imagem hipofisária for equívoca (71). Como opções terapêuticas para os TSH-omas temos a cirurgia transesfenoidal, a radioterapia e/ou o uso de drogas. As metas do tratamento são prevenir ou aliviar os efeitos tumorais compressivos e restaurar o eutiroidismo.

\section{Cirurgia Transesfenoidal}

É classicamente considerada a terapêutica inicial de escolha para os TSH-omas (66,71-73). Entretanto, como eles geralmente são grandes - $90 \%$ são macroadenomas (67) - e localmente invasivos, o percentual de cura (definida como normalização hormonal e retirada completa do adenoma) tem se revelado bastante insatisfatório, variando de 35 a $38 \% \mathrm{~cm}$ três séries $(66,72,73)$. Em uma dessas séries, com 120 pacientes, normalização da função tiroideana foi obtida $\mathrm{cm}$ 66\% dos casos, mas a retirada completa do tumor só foi possível em 33\% (66). Entre os 16 pacientes acompanhados por Sanno e cols (74), controle do hipertiroidismo aconteceu em $62,5 \%$ dos submetidos à cirurgia e em $87,5 \%$ daqueles que receberam terapia adicional com radioterapia ou drogas. A cura cirúrgica dos TSH-omas é mais provável em pacientes albergando microadenomas ou macroadenomas com mínima extensão supra-selar $(66,68)$.

\section{Radioterapia}

Tem sido utilizada sobretudo em casos de insucesso cirúrgico (69). Nesta situação, a radioterapia propiciou normalização dos hormônios tiroideanos em cerca de dois terços dos pacientes (66). Entre 14 pacientes tratados apenas com irradiação hipofisária, controle do hipertiroidismo ocorreu em $43 \%(66,72)$.

\section{Tratamento Medicamentoso}

\section{1) Agonistas Dopaminérgicos (DAs)}

Eficácia clínica. Há dados escassos sobre a eficácia dos DAs nos TSH-omas, com resultados geralmente insatisfatórios (52). Tal fato poderia resultar da limitada presença de receptores dopaminérgicos nesses tumores $(71,75)$. Quando usada em 24 pacientes, a bromocriptina $(20-60 \mathrm{mg} /$ dia) normalizou a função tiroideana em apenas $2(8,3 \%)$, sem modificação nos níveis de TSH $(76,77)$. Em um outro paciente tratado, observou-se modesta diminuição do TSH e redução de $28 \%$ no tamanho do adenoma (78). Mais recentemente, normalização da função tiroideana $\mathrm{e}$ importante redução tumoral foram relatadas em um paciente tomando $30 \mathrm{mg} /$ dia de BRC (79). A administração da cabergolina $(0,25 \mathrm{mg}$ duas vezes/semana) a um indivíduo com um adenoma co-secretor de prolactina permitiu a reversão do hipertiroidismo, sem alteração nas dimensões tumorais (80).

\section{2) Análogos da Somatostatina}

$\mathrm{O}$ uso destas drogas em pacientes com TSH-omas baseia-se no fato que vários desses tumores contêm receptores para somatostatina (81) e que a administração aguda de somatostatina e seus análogos levou a um rápido decréscimo nos níveis séricos de TSH (em média, $60 \%$ ), na maioria dos casos $(72)$.

Eficácia clínica. Os análogos da somatostatina têm sido utilizados sobretudo em pacientes não curados pela cirurgia $(75,82,83)$. No entanto, sua eficácia como terapia única dos TSH-omas já foi demonstrada (84). A dose da octreotida necessária para normalização dos níveis do TSH geralmente é menor do que a requerida para normalizar o GH nos casos de acromegalia $(52,66)$. Uma análise de 73 pacientes mostrou que o uso da octreotida 
possibilitou redução e normalização do TSH em, respectivamente, $92 \%$ e $79 \%$ dos pacientes, enquanto níveis normais dos hormônios tiroideanos aconteceram em 95\% (tabela 3) (66). Melhora da visão e redução tumoral (variando de mínima a $70 \%$ ) foram observadas em $75 \% \mathrm{e}$ $52 \%$, respectivamente. Taquifilaxia e escape ocorreram, respectivamente, em $22 \%$ c $10 \%$ dos casos. Em outro estudo, escape aconteceu após 5 meses de resposta favorável (85). Uma verdadeira resistência a octreotida apenas foi documentada em $4 \%$ dos TSH-omas $(83,86)$. Dramática melhora nos distúrbios visuais pode ser evidenciada dentro de poucas horas do início do tratamento, mesmo na ausência de redução tumoral $(68,82)$. Octreotida (100mg SC, duas a três vezes/dia) pode também ser útil para o controle pré-operatório do hipertiroidismo, nos casos não-responsivos às tionamidas (66). Ela pode também ser empregada para induzir redução do tamanho do tumor, facilitando sua retirada cirúrgica (74).

Com o lanreotide, análogo de ação prolongada (30 mg IM a cada 10-15 dias), observou-se diminuição dos níveis do TSH e da subunidade- $\alpha$ em 75\% de 30 pacientes, com restauração do eutiroidismo na maioria dos casos (87). Redução do tumor ocorreu em $50 \%$ e melhora da visão, em $65 \%$. Taquifilaxia e resistência não foram observadas. Em um estudo mais recente, o uso dessa droga permitiu a normalização do TSH e dos hormônios tiroideanos em 13 de 16 pacientes $(81 \%)(88)$.

\section{3) Outras Drogas}

As tionamidas (metimazol e propiltiouracil) mostram-se úteis para restaurar o eutiroidismo no pré-operatório, mas não devem ser empregadas no manuseio contínuo dos TSH-omas devido ao risco de acelerarem a agressividade e o crescimento tumoral por um aumento secundário da secreção do TSH (68). Macroadenomas invasivos foram detecta-

Tabela 3. Eficácia da terapia com octreotida $(50-750 \mu \mathrm{g}$ 2-3 vezes/dia, SC) em 73 pacientes com tirotrofinomas (modificado da ref. 66).

\begin{tabular}{ll} 
Redução do TSH & \\
Melhora da visão & $92 \%$ \\
Normalização do TSH & $75 \%$ \\
Redução da massa tumoral & $79 \%$ \\
Redução da subunidade- $\alpha$ & $52 \%$ \\
Taquifilaxia & $93 \%$ \\
Normalização dos hormônios tiroideanos & $22 \%$ \\
$\quad$ Estudos a curto prazo & $72 \%$ \\
Estudos a longo prazo & $95 \%$ \\
Escape & $10 \%$ \\
Resistência & $4 \%$ \\
Intolerância & $7 \%$ \\
Redução do tamanho do bócio & $18 \%$ \\
\hline
\end{tabular}

dos em $49 \%$ dos pacientes que usaram tionamidas (por causa de um diagnóstico incorreto de doença de Graves) e em $27 \%$ dos que não o fizeram (71). Betabloqueadores, como o propranolol, permitem um alívio sintomático temporário e podem ser úteis como terapia adjunta para controle do hipertiroidismo (68). Triiodotironina e L-tiroxina usualmente não são eficazes na supressão dos níveis de TSH; quando o fazem, freqüentemente não são toleradas por exacerbarem o hipertiroidismo (68). A despeito de suprimir agudamente a secreção do TSH, a terapia com dexametasona não está recomendada $\mathrm{em}$ função de seus sabidos efeitos colaterais (68).

\section{COMENTÁRIOS}

Os análogos somatostatínicos (SRIFa) potencialmente apresentam um papel relevante no manuseio dos TSH-omas, uma vez que a terapia a longo prazo com octreotida permite normalização do TSH em $80 \%$ dos casos e dos hormônios tiroideanos em $95 \%$, enquanto com o uso do lanreotide atingiu-se o eutiroidismo em $75-81 \%$ dos pacientes. Em contrapartida, a cirurgia, sozinha ou combinada à radioterapia hipofisária, possibilita o controle da função tiroideana em, no máximo, dois terços dos pacientes, ao passo que a radioterapia isoladamente restaura o eutiroidismo em menos de $\mathbf{5 0} \%$ dos pacientes (tabela 4). Assim, os SRIFa podem ser considerados como alternativa para cirurgia em pacientes selecionados, tais como, na presença de tumores grandes com baixa probabilidade de cura cirúrgica, indivíduos idosos ou quando houver contraindicação ou recusa para a cirurgia. Da mesma forma, devido aos potenciais riscos e complicações da radioterapia (hipopituitarismo, carcinogênese cerebral secundária, etc), os SRIFa representam uma atraente alternativa terapêutica para os casos de hipertiroidismo persistente após a cirurgia. Nos pacientes com hiperprolactinemia associada, cabergolina pode eventualmente ser útil em substituição aos SRIFa (figura 3).

Tabela 4. Resultados das diversas formas de terapia para os TSH-omas

\begin{tabular}{lll}
\hline Tipo de tratamento & $\begin{array}{l}\text { \% normalização dos } \\
\text { hormônios tiroideanos }\end{array}$ & Referência \\
\hline Cirurgia & $62,5-66$ & 66,74 \\
Radioterapia & 43 & 66,72 \\
Cirurgia + Radioterapia & 62 & 66 \\
Octreotida & 95 & 66 \\
Lanreotide & $75-81$ & 87,88 \\
Bromocriptina & 8 & 76,77 \\
\hline
\end{tabular}

Arq Bras Endocrinol Metab vol 44 nำ 6 Dezembro 2000 


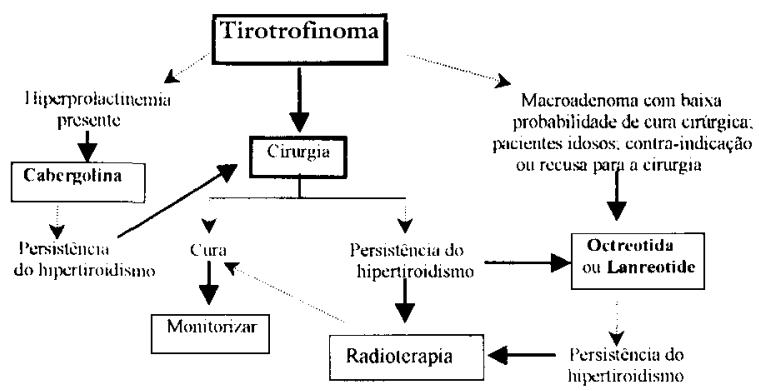

Figura 3. Algoritmo proposto para manuselo dos tirotrofinomas (a cirurgia, a priori, é o tratamento de escolha; a terapia medicamentosa fica reservada para casos selecionados)

\section{ADENOMAS CLINICAMENTE NĀO-FUNCINANTES}

Adenomas clinicamente não-funcionantes (ACNF), responsáveis por 25 a $30 \%$ de todos os adenomas hipofisários e pela maioria dos macroadenomas, são assim chamados por não causarem síndromes clínicas de hipersecreção hormonal $(89,90)$. Entretanto, até $90 \%$ ou mais desses tumores produzem gonadotrofinas e/ou suas subnidades a e b, as quais, na maioria das vezes, apenas são detecadas por estudo imunocitoquímico ou técnicas de biologia molecular $(52,91)$. Podemos, contudo, ocasionalmente observar níveis séricos elevados do FSH intacto (em até $15 \%$ dos pacientes), FSH- $\beta$ (em até $37 \%$ ), subunidade- $\alpha$ (em cerca de $20 \%$ ) ou, mais raramente, LH $(71,92,93)$. Em uma minoria de casos, os ACNF são verdadeiramente não-secretores ou representam adenomas corticotróficos, somatotróficos ou tirotróficos silenciosos $(71,94,95)$.

Como os ACNF não cursam com uma síndrome hormonal característica, quando detectados muitas vezes se apresentam como grandes macroadenomas com significante extensão extra ou supra-selar, sintomas compressivos (cefaléia, distúrbios visuais) e manifestaçōes de hipopituitarismo $(71,89)$. Menos comumente, neuropatias cranianas, síndrome do seio cavernoso e apoplexia pituitária podem acontecer (7l). Os ACNF podem também ser diagnosticados ao acaso, como incidentalomas hipofisários, num paciente completamente assintomático (96). O principal diagnóstico diferencial dos ACNF é com os macroprolactinomas (91); enquanto nestes últimos, níveis de prolactina habitualmente excedem $200 \mathrm{ng} / \mathrm{ml}$, nos ACNF a hiperprolactinemia (resultante de compressão da haste) geralmente é inferior a $100 \mathrm{ng} / \mathrm{ml}(97,98)$. É preciso estar atento, contudo, à possibilidade de se ter valores falsamente baixos da prolactinemia, devido ao chamado efeito gancho, em indivíduos com macroprolactinomas (99).

As opções terapêuticas para os $\mathrm{ACNF}$ são a cirurgia, radioterapia e drogas. A necessidade e a urgência de tratamento dependerá do tamanho do tumor e, principalmente, da presença ou não de sintomas neuro-oculares (91). Pacientes assintomáticos com microadenomas ou pequenos macroadenomas podem apenas requerer seguimento através de ressonância magnética periódica $(91,100)$.

\section{Cirurgia}

A cirurgia tem sido considerada o tratamento de escolha para os ACNF por ser o método mais eficiente para se conseguir redução tumoral e, conseqüentemente, descompressão das vias ópticas e da hipófise normal $(91,98)$. Em mais de $90 \%$ dos casos, a adenomectomia por via transesfenoidal é exequível (91), mas a retirada da massa tumoral freqüentemente não é total, devido ao seu grande tamanho (98). A cirurgia resulta em melhora da visão em 44 a $80 \%$ dos pacientes com alterações nos campos visuais (91,101-105), porém eventualmente pode agravá-las (103). Pode também melhorar ou reverter um hipopituitarismo pré-existente (106), mas hipopituitarismo, diabetes insipidus permanente, e complicações locais (meningite, abscessso, rinoliquorréia, etc) acontecem em menos de 7\% pacientes operados (107). A freqüência dessas complicações é significativamente maior nas mãos de neurocirurgiōes menos experientes e em caso de cirurgia ou radiocirurgia prévias (107). Outro problema é a recidiva pós-cirúrgica que, além de comum, pode se manifestar após vários anos (108). Entre 377 pacientes, a recidiva tumoral, 5 a 10 anos após a cirurgia, variou de 12 a $69 \%$ (média de 26\%) (101). Entre 426 pacientes que recebcram radioterapia após a cirurgia, a taxa de recidiva variou de 4 a $21 \%$ (média de $11 \%$ ) (101).

\section{Radioterapia}

A radioterapia permite melhorar e estabilizar as alterações visuais, bem como reduzir o tamanho dos remanescentes tumorais, em mais de $40 \%$ dos pacientes (103). Possibilita também menor ocorrência de recidiva/recrescimento tumoral após a cirurgia $(90,91,101,108)$, conforme mencionado. No entanto, tem como complicação muito freqüente o hipopituitarismo parcial ou total (109). Em uma série, a incidência de deficiência de GH, ACTH, TSH e gonadotrofinas foi, respectivamente, de 
$100 \%, 77 \%, 42 \%$ e $96 \%$ (71). A possibilidade de lesão actínica no nervo óptico ou de carcinogênese cerebral secundária, ainda que muito pequena, deve também ser considerada na análise individual dos riscos e benefícios do tratamento radioterápico (91).

O emprego sistemático da irradiação hipofisária $\mathrm{cm}$ pacientes operados tem sido defendido por alguns autores $(102,108)$; no entanto, devido aos scus potenciais riscos e complicações, a tendência maior é reservá-la para pacientes que sejam pobres candidatos à cirurgia, tenham tumores cirurgicamente inacessíveis ou se apresentem com um resíduo tumoral significativo após a descompressão cirúrgica $(71,90,98,109)$. Também representa uma alternativa à cirurgia em caso de tumores recidivantes ou que cresçam durante o seguimento $(71,98)$.

\section{Tratamento Medicamentoso}

Três classes de drogas têm sido utilizadas no manuseio dos ACNF: agonistas dopaminérgicos, analógos somatostatínicos e análogos do GnRH $(71,91)$. Sua maior finalidade seria propiciar redução das dimensões tumorais, evitando-se assim a necessidade de cirurgia ou radioterapia, mas os resultados desse tratamento têm sido, cm geral, insatisfatórios $(52,71)$.

\section{Agonistas Dopaminérgicos (DA)}

Eficcácia clínica. A introdução dos DA na terapia medicamentosa dos ACNF foi baseada na observação de que receptores dopaminérgicos estavam presentes in vitro nas células desses tumores. A maior parte dos estudos envolveu a BCR, tendo sido observado que, na maioria das vezes, ela não modificou o tamanho do adenoma, o qual, algumas vezes, até aumentou (111). Dados da literatura mostram melhora visual em 0 a $32 \%$ dos pacientes tratados (ocasionalmente, mesmo na ausência de diminuição do adenoma), enquanto a ocorrência de redução tumoral, visível em exames por imagem, variou de 0 a $20 \%$ (91,111-118). Essa redução foi geralmente bastante modesta, mas às vezes excedeu $50 \%$ (117). O período para que ocorresse foi bastante variável dias a semanas $(110,116)$ ou somente após 2 anos de tratamento $(119,120)$-, mas na maioria dos casos aconteceu dentro de um ano (111). Uma revisão de 84 casos, oriundos de 7 séries, mostrou redução tumoral em $8 \%$ dos pacientes, e em $15 \%$ naqueles tratados por mais de um ano (121), sugerindo um maior beneficio da terapia mais prolongada. Em alguns poucos pacientes, o uso da BCR possibilitou diminuição ou normalização dos níveis de FSH, LH e subunidade- $\alpha(122,123)$. Dentre 10 pacientes que acompanhamos em uso de BRC, na dose de 7,5 a 20 $\mathrm{mg} /$ dia, observamos diminuição do volume do adenoma em 1 ( $13 \%)$ e melhora dos campos visuais em $3(30 \%)$. A pobre resposta dos ACNF a BRC, a despeito da presença de receptores dopaminérgicos, pode ser atribuída à baixa densidade dos receptores, à expressão desses receptores somente em uma minoria de células tumorais ou à eventual presença de defeitos pós-receptor (121).

Somente poucos estudos avaliaram a eficácia da quinagolida $\mathrm{cm}$ ACNF (124-126). O uso dessa droga em 12 pacientes, tratados com 0,3-0,6 $\mathrm{mg} /$ dia, por 3-12 meses, resultou em redução dos níveis de gonadotrofinas e/ou subunidade- $\alpha \mathrm{em}$ todos eles, enquanto significante redução tumoral foi documentada $\mathrm{em}$ apenas $4(33 \%)(124-126)$. Os dados sobre a utilidade da $\mathrm{CAB}$ em $\mathrm{ACNF}$ são ainda bastante escassos (52). Em um estudo recente, Colao e cols (127) analisaram a eficácia da cabergolina e quinagolida em 10 pacientes, observando uma significante redução tumoral (maior ou igual a $50 \%$ ) apenas nos dois casos em que se observou uma intensa captação hipofisária de 123I-metoxibenzamida (123I-IBZM), traçador que permite a deteç̧ão de receptores dopaminérgicos $\mathrm{D}_{2}$.

\section{Análogos Somatostatinicos}

Eficácia clinica. Receptores somatostatínicos (SSTR) foram detectados através do octreoscan em 25 a $75 \%$ dos ACNF $(91,128,129)$. No entanto, os efeitos benéficos da terapia com octreotida foram variáveis e infreqüentes $(98,102)$, correlacionandose pobremente com a presença dos $\operatorname{SSTR}(81,130)$. Em 13 estudos, envolvendo 58 pacientes com ACNF, a freqüência média de redução tumoral (geralmente, de limitada magnitude) e melhora dos distúrbios visuais foi de $24 \%$ e $35 \%$, respectivamente (131). Melhores resultados foram observados em um estudo multicêntrico francês no qual, na dose de $300-600 \mu \mathrm{g} / \mathrm{dia}$, melhora visual ocorreu em $46 \%$, $61 \%$ e $41 \%$ dos pacientes após, respectivamente, 4 , 30 e 60 dias de tratamento (131). Depois de dois meses de tratamento, redução tumoral se fez presente em $3 / 7(43 \%)$ pacientes, com intensidade variável de 26 a $73 \%$ (131). Contudo, convém salientar que nesse estudo só foram mantidos os pacientes que apresentaram melhora precoce da função visual com a octreotida. Supressão parcial da secreção de gonadotrofinas e subunidade-a pclo uso da octreotida foi também relatada em alguns pacientes, sendo esse efeito muitas vezes independente da redução 
tumoral $(132,133)$. Recentemente, foi demonstrado que o uso pré-operatório de lanreotide resultou em significante redução das dimensões de 1 dentre 4 ACNF (134).

Melhora da visão e da cefaléia podem acontecer dentro de poucas horas do início da terapia com a octreotida, na ausência de qualquer mudança no volume dos $\mathrm{ACNF}(52,102)$. Isso sugere que a octreotida poderia exercer efeitos diretos sobre a retina ou o nervo óptico $(81,131)$. Poderia também refletir efeitos da droga sobre a vasodilatação cerebrovascular (7l). Em apoio a essas hipóteses, melhora dos defeitos visuais foi relatada em um paciente com um ACNF desprovido de receptores somatostatínicos (135).

\section{Análogos do GnRH}

Eficácia clínica. Os análogos agonistas do GnRH foram testados em um limitado número de indivíduos com adenomas secretores de gonadotrofinas, com resultados insatisfatórios. Em 9/11 (82\%) pacientes, essas drogas tiveram um efeito nulo ou exacerbaram a secreção hormonal, sem modificar o tamanho do tumor (134). Em um outro estudo, nafarelina foi administrada durante um ano a 8 pacientes com adenomas gonadotróficos, sem que

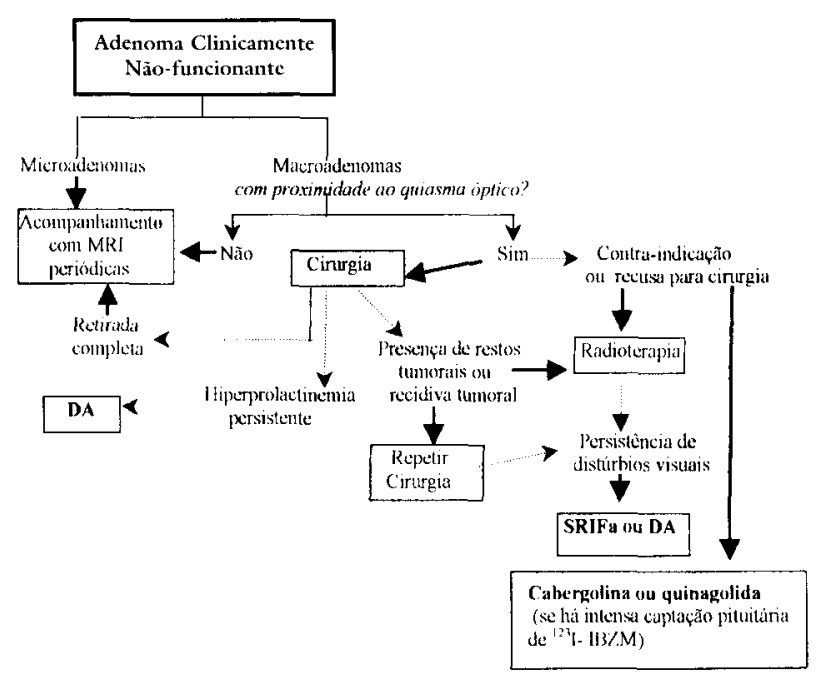

Figura 4. Algoritimo proposto para o manuseio dos adenomas clinicamente näo-funcionantes (SRIFa ou DA estão melhor indicados para os casos de contra-indicaçõo ou recusa para cirurgia, ou diante da persistência de distúrbios visuais após cirurgia ou radioterapia; a terapia com os DA cabergolina ou quinagolida poderia eventualmente ser tentada antes da radioterapia em pacientes com intensa captaçāo pituitária de 123|- (BZM). $(\mathrm{MR} \mid=$ ressonância magnética; $\mathrm{DA}=$ agonista dopam inérgico; $S R I F a=$ análogo somatostatínico, $123|-| B Z M=$ 123/-metoxibenzamida). tivesse havido redução tumoral ou melhora dos distúrbios visuais (7l). O uso de Nal-Glu GnRH, um potente análogo antagonista do $\mathrm{GnRH}$, reduziu os níveis circulantes de FSH em 5 pacientes, mas tampouco modificou o tamanho do tumor (136).

\section{COMENTÁRIOS}

Dcvido ao seu habitual cfeito limitado em reduzir o tamanho dos adenomas clinicamente não-funcionantes (ACNF), análogos somatostatínicos (SRIFa) e agonistas dopaminérgicos (DA) devem ser considerados, principalmente, para os casos não resolvidos com a cirurgia ou com contra-indicação cirúrgi$\mathrm{ca}$, nos quais se aguardam os efeitos da radioterapia. Uma intensa captação hipofisária à cintilografia com I-metoxibenzamida parece, contudo, identificar um subgrupo de pacientes propensos a apresentar uma significante redução tumoral com a terapia crônica com cabergolina ou quinagolida. DA podem também ser úteis no manuseio da hiperprolactinemia persistente após a cirurgia ou radioterapia. Uma outra indicação potencial para a terapia medicamentosa, sobretudo para os SRIFa, seria a presença de distúrbios visuais importantes causados por resíduos tumorais, em pacientes previamente submetidos à cirurgia e/ou radioterapia (figura 4). Os análogos do GnRH não estão recomendados no manuseio dos ACNF, uma vez que não propiciam redução tumoral e, eventualmente, podem exacerbar a hipersecreção hormonal.

$O$ desenvolvimento de uma efetiva terapia medicamentosa para os ACNF é imperioso, uma vez que a cirurgia freqüientemente não é curativa, a taxa de recidiva tumoral é elevada (em média, em 26\%) e a radioterapia, ainda que eficaz em reduzir a massa tumoral, muito freqüentemente causa hipopituitarismo.

\section{REFERÊNCIAS}

1. Atkinson $\mathrm{AB}$. Current therapy - The treatment of Cushing's syndrome. Clin Endocrinol (Oxf) 1991;34:507-13.

2. Vilar L, Cavalcanti N. Tratamento da Síndrome de Cushing. In: Vilar L, Castellar E, Moura E, Leal E, et al, eds. Endocrinologia Clínica. Rio de Janeiro:Medsi، 1999:249-62.

3. Vilar L, Freitas MC, Moura E, Machado AC, et al. Doença de Cushing causada por macroadenomas Relato de 7 casos". Arq Brasil Endocrinol Metab 1996;40 (supl.2):S221.

4. Burke CW, Adams CBA, Esiri MM, Morris C, Bevan JS. Transsphenoidal surgery for Cushing's disease: does what is removed determine the endocrine outcome? Clin Endocrinol (Oxf) 1990;33:527-37 
5. Laws ER Jr, Thapar K. Pituitary surgery, Endocrinol Metab Clin North Am 1999;28:119-31.

6. Blevins LS Jr, Christy JH, Khajavi M, Tindall GT, et al. Outcomes of therapy for Cushing's disease due to adrenocorticotropin-secreting pituitary macroadenomas. J Clin Endocrinol Metab 1998:83:63-7

7. Orth DN, Kovacs WJ, DeBold CR. The adrenal cortex. In: Wilson JD, Foster DW. eds. Williams Textbook of Endocrinology. Philadelphia:Saunders, 1992:489-619.

8. Pereira MAA, Jugue SM, Moura OLD, Gross K, et al. Doença de Cushing: avaliação diagnóstica, terapêutica e prognóstica. Rev Ass Med Brasil 1992;38:48-54.

9. Czepielewski MA, Rollin GAFS, Gross JL, Ferreira NP, et al. Resultados cirúrgicos na doença de Cushing. Arq Brasil Endocrinol Metab 1999:43(supl. 2):S409.

10. Miller JW, Crapo L. The medical treatment of Cushing's syndrome. Endocr Rev 1993; 14:443-58.

11. Orth DN, Liddle GW. Results of treatment in 108 patients with Cushing's syndrome. N Engl J Med 1971;285:243-7.

12. Aristizabal S, Caldwell WL, Avila J, Mayer EG. Relationship of time dose factors to tumour control and complications in the treatment of Cushing's disease by irradiation. Int J Radiat Onc Biol Phys 1977:2:47-54.

13. Sharpe GF, Kendal-Taylor P. Prescott RWG, Ross WM, et al. Pituitary function following megavoltage therapy for Cushing's disease: long-term follow-up. Clin Endocrinol (Oxf) 1985:22:169-77.

14. Howlett TA, Plowman PN, Wass JA, Rees LH, Besser GM Megavoltage pituitary irradiation in the management of Cushing's disease and Nelson's syndrome: long-term follow-up. Clin Endocrinol (Oxf) 1989;31:629-32.

15. Littley MD, Shalt SM, Beardwell CG, Ahmed SR, Sutton ML. Long-term follow-up of low-dose external pituitary irradiation for Cushing's disease. Clin Endocrinol (Oxf) 1990;33:445-55.

16. Vicente A, Estrada J, de la Cuerda C, Astigarra B, et al. Results of external pituitary irradiation after unsuccessful transsphenoidal surgery in Cushing's disease. Acta Endocrinol (Copenh) 1991;125:470-4

17. Molitch ME. Management of persistent or recurrent functional pituitary adenomas following surgery. Endocrinologist 1995:5:457-6

18. Estrada J, Boronat M. Mielgo M, Magallon R, et al. The long-term outcome of pituitary irradiation after unsuccessful transsphenoidal surgery in Cushing's disease. N Engl J Med 1997;336:172-7.

19. Leinung MC, Zimmerman D. Cushing's disease in children. Endocrinol Metab Clin North Am 1994;23:629-39.

20. Jenkins PJ, Trainer PJ, Plowman PN, et al. The long outcome after adrenalectomy and prophylatic pituitary radiotherapy in adrenocorticotropin-dependent Cushing's syndrome J Clin Endocrinol Metab 1995;80:165-71.

21. Plowman PN. Pituitary adenoma radiotherapy - when and how? Clin Endocrinol 1999:51:265-72

22. Degerblad M. Rahn T, Bergstrand $G$. Thorén $M$. Longterm results of stereotactic radiosurgery to the pituitary gland in Cushing's disease. Acta Endocrinol (Copenh) 1986; 112:310-4.

23. Imai T, Funahashi $H$, Tanaka $Y$, Tobinaga J, et al. Adrenalectomy for the treatment of Cushing's syndrome: results in 122 patients and long-term follow-up studies. World J Surg 1996:20:781-6

24. Trainer PJ, Besser GM. Cushing's syndrome: therapy directed at the adrenal glands. Endocrinol Metab Clin North Am 1994:23:571-84.

25. Miossec $P$, Archambeaud-Mouveroux F, Teissier MP. Inhibition of steroidogenesis by ketoconazole - Therapeutic uses, Ann Endocrinol (Paris) 1997:58:494-502.

26. Stalla GK, Stalla J, Huber M, et al. Ketoconazole inhibits corticotropic cell function in vitro. Endocrinology 1988; 122:618-23.

27. Sonino N, Boscaro M. Medical therapy for Cushing's disease. Endocrinol Metab Clin North Am 1999;28:211-22.

28. Sonino N, Boscaro M, Paoletta A, Mantero F, Zillioto Ketoconazole treatment in Cushing's syndrome Experience in 34 patients. Clin Endocrinol (Oxf) 1991: 35:347-52.

29. Tabarin A, Navarrane A, Guerin J, Corcuff JB, Parmiex $M$, Roger $P$. Use of ketoconazole in the treatment of Cushing's disease and ectopic ACTH syndrome. Clin Endocrinol (Oxf) 1991:34:63-9.

30. Berwaents J, Verhelst JA, Verhaert GC, Verhaegen A, Abs $\mathrm{RE}$. Corticotropin-dependent Cushing's syndrome in older people: presentation of five cases and therapeutical use of ketoconazole. J Am Geriatr Soc 1998;46:880-4.

31. Spagnolli W, Ramponi C, Davi MV, Francia G. Cushing's disease associated with empty sella: a clinical case treated for years with ketoconazole. Ann Ital Med Int $1996 ; 11: 275-8$

32. Moncet D, Morando JD, Katz SB, Pitoia F, et al. Ketoconazole therapy in Cushing's syndrome. Proc $82^{\text {nd }}$ Annual Meeting of the Endocrine Society, Toronto, Canada, 2000 (Abstract P1-1932)

33. Diop SN, Warnet A, Duet M, Firmin C, Mosse A, Lubetsky $\mathrm{J}$. Long-term treatment of ketoconazole in the treatment of Cushing's disease and ectopic ACTH syndrome. Clin Endocrinol (Oxf) 1991:34:63-9.

34. Berwaerts J, Verhelst J, Mahler C, Abs R.Cushing's syndrome in pregnancy treated by ketoconazole: case report and review of the literature. Gynecol Endocrinol 1999:13:175-82.

35. Verhelst JA, Trainer PJ, Howlet TA, Perry L, et al. Short and long-term responses do metyrapone in the medical management of 91 patients with Cushing's syndrome. Clin Endocrinol (Oxf) 1991:35:169-78.

36. Jeffcoat WJ, Rees LH, Tomlin S, Jones AE, Edwards CRW, Besser GM. Metyrapone in long-term management of Cushing's disease. Br Med J 1977:2:215-17.

37. Donckier J, Burrin JM, Ramsay ID, Joplin GF. Successful control of Cushing's disease in the elderly with long term metyrapone. Postgrad Med J 1986;62:727-30.

38. Misbin RI, Canary J, Willard D. Aminoglutethimide in the management of Cushing's syndrome. J Clin Pharmacol $1976 ; 16: 645-51$. 
39. Drake W M. Perry LA, Hinds CJ, Lowe DG, Reznek RH, Besser GM. Emergency and prolonged use of intravenous etomidate to control hypercortisolemia in a patient with Cushing's syndrome and peritonitis. J Clin Endocrinol Metab 1998:83:3542-4.

40. Semple CG. Beastall GH, Gray CE, et al. Trilostane in the management of Cushing's syndrome. Acta Endocrinol (Copenh) 1983;102:107-10

41. Aron DC, Findling JW. Tyrrell JB. Cushing's disease. Endocrinol Metab Clin North Am 1987:16:705-30.

42. Luton JP, Mahoudeau JA, Bouchard Ph, et al. Treatment of Cushing's disease by o,p'DDD. Survey of 62 cases. $\mathbf{N}$ Engl J Med 1979;300:459-64.

43. Schteingart DE, Tsao HS, Taylor Cl, Mckenzie A, et al. Sustained remission of Cushing's disease with mitotane and pituitary irradiation. Ann Intern Med 1980:92:613-9.

44. Maher VMG, Trainer PJ, Scoppola A, et al. Possible mechanisms and treatment of $0, P^{\prime}$ DDD-induced hypercholesterolemia, Q J Med 1992:84:671-9.

45. Kennedy AL, Sheridan B, Montgomery DAD. ACTH and cortisol response to bromocriptine and results of longterm therapy in Cushing's disease. Acta Endocrinol (Copenh) 1978:89:462-8.

46. Boscaro M, Benato M, Mantero F. Effect of bromocriptine in pituitary dependent Cushing's syndrome. Clin Endocrinol (Oxi) 1983;19:485- 91.

47. Hale AC, Coates JP, Doniach I, Howlett TA, et al. A bromocriptine-responsive corticotroph adenoma secreting alpha-MSH in a patient with Cushing's disease. Clin Endocrinol (Oxf) 1988;28:215-23.

48. Hayashi H, Mercado-Assis LB, Murayama M, Yakamita N, et al. Reduction of pituitary size with clinical and biochemical improvement with bromocriptine in a normoprolactinemic Cushing's disease. Endocrinol Jpn $1990: 37: 875-82$

49. Mercado-Assis LB, Yasuda K, Murayama M. Mune T, Morita H. Miura K. Benefitial effects of high daily dose of bromocriptine treatment in Cushing's disease. Endocrinol Jpn 1992;39:385-95.

50. Yasuda K. Miura K. Unique type of Cushing's disease in clinical profile: cyclic Cushing's disease and Cushing's disease with favorable outcome to a high daily dose of bromocriptine. Nippon Naibunpi Gakkai Zasshi 1994;70:11-6.

51. Koppeschaar HPF, Croughs RJM, Thijssen JHH, Schwarz $F$. Response to neurotransmitter modulating drugs in patients with Cushing's disease. Clin Endocrinol (Oxf) 1986:25:661-7.

52. Colao A, Di Sarno A, Marzullo P, Carolina Di Somma C, et al. New medical approaches in pituitary adenomas. Horm Res 2000:53(suppl. 3):76-87.

53. Lamberts SWJ, Birkenhager JC: Bromocriptine in Nelson's syndrome and Cushing's disease. Lancet 1976:2:811.

54. Whitehead HM, Beacom R, Sheridan B, Atkinson AB The effect of cyproheptadine and/or bromocriptine on plasma ACTH levels in patients cured of Cushing's disease by bilateral adrenalectomy. Clin Endocrinol (Oxf) 1990:32:193-201

55. Pivonello R, Faggiano A, Di Salle F, Filippella M, Lombardi $G$, Colao A. Complete remission of Nelson's syndrome after 1-year treatment with cabergoline. J Endocrinol Invest 1999:22:860-5.

56. Krieger DT. Physiopathology of Cushing's disease. Endocr Rev 1991:4:22-43

57. Tanakol R, Alagol F, Azizlerli H, Sandalci O, et al. Cyproheptadine treatment in Cushing's disease. J Endocrinol Invest 1996; 19:242-7.

58. Elias NA, Gwuinup G, Valenta LJ. Effects of valproic acid, naloxone and hydrocortisone in Nelson's syndrome and Cushing's disease. Clin Endocrinol (Oxf) $1981 ; 15: 151-4$

59. Garcia Rojas G, Mangas A, Barba Chacon A. Garcia Osle $M$, et al. Clinical remission in Cushing's disease through treatment with sodium valproate and bromocriptine. Rev Clin Esp 1991:188:37-40.

60. Sartor O, Cutler GB Jr. Mifepristone: treatment of Cushing's syndrome. Clin Obstet Gynecol 1996;39:506-10.

61. van der Lely AJ, Fockin K, van der Mast RC, Lamberts SWJ. Rapid reversal of acute psychosis in Cushing's syndrome with the cortisol receptor antagonist mifepristone (RU 486). Ann Intern Med 1991:114:143-4.

62. Wilson $\mathrm{CB}$. A decade of pituitary microsurgery. The Herbert Olivecrona Lecture. J Neurosurg 1984;61:814-33.

63. Kovacs K. Horvath E. Pathology of pituitary fumours. Endocrinol Metabl Clin North Am 1987:16:529-51.

64. Mukai K. Pituitary adenomas - Immunocytochemical study of 150 tumours with clinicopathologic correlation. Cancer 1983:52:648-53

65. Minderman T, Wilson CB. Thyrotropin-producing pituitary adenomas. J Neurosurg 1993:79:521-7.

66. Beck-Peccoz P. Brucker-Davis F, Persani L, Smallridge RC. Weintraub BD. Thyrotropin secreting pituitary tumors. Endocr Rev 1996; 17:610-38.

67. Beck-Peccoz P, Persani L, Mantovani S, Cortelazzi D, Asteria $C$. Thyrotropin-secreting pituitary tumors. Metabolism 1996:45(suppl 1):75-9.

68. Greenman Y, Melmed S. Thyrotropin-secreting pituitary tumours. In: Melmed S, ed. The Pituitary. Boston:Blackwell Scientific, 1995:546-58.

69. Samuels MH, Ridgway EC. Glycoprotein-secreting pituItary adenomas. Baillière's Clin Endocrinol Metab 1995:9:337-58

70. Gesundheit N, Petrick PA, Nissim M, et al. Thyrotropin-secreting pituitary adenomas: clinical and biochemical heterogeinity. Ann Intern Med 1989; $111: 827-35$.

71. Shomali ME, Katznelson L. Medical therapy for gonadotroph and thyrotroph tumors. Endocrinol Metab Clin North Am 1999:28:223-40. 
72. Smallridge RC. Thyrotropin-secreting pituitary tumours. Endocrinol Metab Clin North Am 1987:16:765-92.

73. Brucker-Davis F, Oldfield EH, Skarulis MC, Doppman JL, Weintraub BD. Thyrotropin-secreting pituitary tumors: diagnostic criteria, thyroid hormone sensitivity, and treatement outcome in 25 patients followed at the National Institutes of Health. J Clin Endocrinol Metab 1999;84:476-86.

74. Sanno N, Terramoto A, Osamura RY. Long-term surgical outcome in 16 patients with thyrotropin pituitary adenoma. J Neurosurg 2000;93:194-200.

75. Chanson P, Orgiazzi J, Derome PJ, et al. Paradoxical response of thyrotropin to L-dopa and presence of dopaminergic receptors in thyrotropin-secreting pituitary adenoma. J Clin Endocrinol Metab 1984:59:542-6.

76. Mcmellan AR, Connell JMC, Alexander WD, Davies LD. Clinical response of thyrotropin-secreting macroadenomas to bromocriptine and radiotherapy. Acta Endocrinol (Copenh) 1988; 19:189-94.

77. Jap TS, Kwok CE, Ho LT. Thyrotropin and prolactin-secreting pituitary tumor - dissociated hormonal response to bromocriptine. Clin Med J 1990:45: 191-5.

78. Wollesen F, Anndersen T, Karle A. Size reduction of extraselar pituitary tumors during bromocriptine therapy. Ann Intern Med 1992;74:690-4.

79. Camacho P, Mazzone T. Thyrotropin-secreting pituitary adenoma responsive to bromocriptine therapy. Endocr Pract 1999:5:257-60

80. Mulinda JR, Hasinsk S, Rose LI. Successful therapy for a mixed thyrotropin- and prolactin-secreting pituitary macroadenoma with cabergoline. Endocr Pract 1999:5:76-9.

81. Lamberts SW, van der Lely AJ, de Herder WW, Hofland LJ. Octreotide. N Engl J Med 1996;334:246-54.

82. Chanson $P$, Weintraub $B D$, Harris $A G$. Octreotide therapy for thyroid-stimulating hormone-secreting pituitary adenomas. A follow-up of 52 patients. Ann Intern Med 1993: 1 19:236-40.

83. Comi RJ, Gesundheit N, Murray L, et al. Response of thyrotropin-secreting pituitary adenomas to a long-acting somatostatin analogue. $\mathrm{N}$ Engl J Med 1987:317:12-7.

84. Prévost $G$, Vantyghem MC. Hober C. Evrard A, et al. Thyrotropic adenoma: review of the literature. A propos of 2 cases. Ann Endocrinol (Paris) 1996:57:194-202.

85. Podaba J, Hnilica P, Makaiova I, Kovacova S, et al. Octreotide in the treatment of thyrotropin-secreting pituitary adenoma. Vnitr Lek 1997;43:607-10.

86. Houdent $\mathrm{CH}$, Armangau MF, Kuhn JM, Delangre T, Tadie $M$, et al. Adénome thyréotrope traité par un analogue de la somatostatine. Ann Endocrinol (Paris) 1989;50:227-31

87. Beck-Peccoz P, Persani L, Fugazzola L, Mannavola D, Asteria C. Thyrotropic adenomas treated with lanreotide. J Endocrinol Invest 1997:20(suppl 7):48-9.

88. Kunn JM, Arlot S, Lefebvre H, Caron P, et al. Evaluation of the treatment of thyrotropin-secreting pituitary adenomas with a slow release formulation of the somatostatin analog lanreotide. J Clin Endocrinol Metab 2000;85:148791.89. Klibansky A. Nonsecreting pituitary tumors. Endocrinol Metab Clin North Am 1987;16:793-804.

90. Shimon I, Melmed S. Management of pituitary tumors. Ann Intern Med 1998; 129:472-83.

91. Cunha Neto MBC, Musolino NR, Bronstein MD. Manuseio dos adenomas hipofisários clinicamente não-funcionantes. In: Vilar L, Castellar E, Moura E, Leal E, et al, eds. Endocrinologia Clínica. Rio de Janeiro:Medsi, 1999:36-48.

92. Katznelson L, Alexander JM, Klibanski A, Clinically nonfunctioning pituitary adenomas. J Clin Endocrinol Metab 1993;76:1089-94

93. Snyder PJ. Gonadotroph cell adenomas of the pituitary. Endocr Rev 1985:6:552-63.

94. Klibansky A, Zervas NT, Kovacs K, Ridgway EC. Clinically silent hypersecretion of growth hormone in patients with pituitary fumors. J Neurosurg 1987;66:806-11.

95. Heshanti HM, Turpin $G$, Kujas $M$, Lam X, et al. The immunocytochemical heterogeneity of silent pituitary adenomas. Acta Endocrinol (Copenh) 1988:1 18:533-7.

96. Molitch ME, Russell EJ. The pituitary "incidentaloma". Ann Intern Med 1990;112:925-31.

97. Bevan JS, Burke CW, Esiri MM, Adams CBT. Misinterpretation of prolactin levels leading to management errors in patients with sellar enlargement. Am J Med 1987:82:29-32.

98. Freda PU, Wardlaw SL. Diagnosis and treatment of pituitary tumors. J Clin Endocrinol Metab 1999:84:3859-66.

99. Cunha Neto MBC, Musolino NR, Bronstein MD, ef al. Macroprolactinomas masquerading as pseudoprolactinoma: the high dose hook effect. Arq Bras Endocrinol Metab 1997:41:98-101.

100.Wilson CB. Extensive personal experience - Surgical management of pituitary tumors. J Clin Endocrinol Metab 1997:82:2381-5.

101. Chanson P. Traitement des adénomes hypophysaires. Presse Med 1998:27:2077-97.

102.Ebersold M, Quast LM, Laws Jr ER, Scheithauer B, Randall $\mathrm{RV}$. Long-term results in transsphenoidal removal of nonfunctioning pituitary adenomas. J Neurosurg 1986; 64:713-9.

103.Sassolas C. Trouillas J, Treluyer C. Perin G. Management of non-functioning pituitary adenomas. Acta Endocrinol (Copenh) 1993;129(suppl. 1):21-6.

104. Harris PE, Afshar F. Coates P. et al. The effects of transsphenoidal surgery on endocrine function and visual fields in patients with functionless pituitary tumors. Q J Med 1989:71:417-27.

105. Comtois R, Beauregard $H$, Somma $M$, Serri $O$, Hardi J. The clinical and endocrine outcome to transsphenoidal microsurgery of non-secreting pituitary adenomas. Cancer 1991;68:860-6.

106. Arafah BM. Reversible hypopituitarism in patients with large non-functioning pituitary adenomas. J Clin Endocrinol Metab 1986:62:1173-9 
107. Laws ER Jr, Thapar K. Pituitary surgery. Endocrinol Metab Clin North Am 1999:28:119-31.

108. Turner HE, Stratton IM. Byrne JV, Adams CBT, Wass JAH Audit of selected patients with non-functioning pituitary adenomas without irradiaton - a follow-up study. Clin Endocrinol (Oxf) 1999:51:281-4

109.Colao A, Cerbone G. Cappbianca P. Ferone D, et al. Effect of surgery and radiotherapy on visual and endocrine function in nonfunctioning pituitary adenomas. J Endocrinol Invest 1998;21:284-90.

110.D'Emdem MC. Harrison LC. Rapid improvement of visual fields following bromocriptine treatment of patients with non-functioning pituitary adenomas. Clin Endocrinol (Oxi) 1986:25:697-702.

111.Van Schaardenburg D, Roelfsema F, Van Seters AP, ef al. Bromocriptine therapy for non-functioning pituitary adenoma. Clin Endocrinol (Oxi) 1989:30:475-84

112. Bevan JS, Burke CW. Non-functioning pituitary adenomas do not regress during bromocriptine therapy but possess membrane-bound dopamine receptors that bind bromocriptine. Clin Endocrinol (Oxf) 1986:25:56172

113. Grossman A, Ross R, Charlesworth M, Adams CBT, et al. The effect of dopamine agonist therapy on large functionless pituitary tumours. Clin Endocrinol (Oxi) 1985;22:679-86.

114.Zarate A, Moran C, Kleriga E, Loyo M, et al. Bromocriptine therapy as pre-operative adjunct of non-functioning pituitary macroadenomas. Acta Endocrinol (Copenh) 1985; 108:445-50.

115.Gasser RW, Mueller-Holzner E, Skrabal F, Mayr U, et al Macroprolactinomas and functionless pituitary tumours. Immunostaining and effect of dopamine agonist therapy. Acta Endocrinol (Copenh) 1987:1 16:253-9.

116. Verde $G$, Oppizzi $G$, Chiodini PG, Dallabonzana D. Lucarelli $G$, Liuzzi A. Effect of chronic bromocriptine administration on tumor size in patients with "nonsecreting" pituitary adenomas. J Endocrinol Invest 1985:8:113-5.

117.Liuzzi A, Dallabonzana D, Oppizzl G, Arrigoni GL, et al. is there a real medical treatment for "non-secreting" pituitary adenomas? In: Faglia $G$, Beck-Peccoz P. Ambrosi B. Travaglini P. Spada A, Editors, Pituitary Adenomas: new trends in basic and clinical research. Amsterdam. Elsevier. 1991:383-90

118. Pullan PT, Khangure MS, Carroll WM, Vaughan RJ Charkera TMH. Management of extrasellar pituitary tumours with bromocriptine treatment: comparison with prolactin and non-functioning tumours using half-field visual evoked potentials and computerized tomography. Austr N Zeal J Med 1985; 15:203-8.

119.Johnston DG. Hall K, McCregor A. Ross WM, et al. Effect of chronic bromocriptine therapy for 'non-functioning' pituitary fumors. Am J Med 1981;71:1059-61.

120. Wollesen F, Andersen T, Karle A. Size reduction of extrasellar pituitary tumors during bromocriptine treatment. Ann Intern Med 1982;96:281-6.
121.Bevan JS, Webster J, Burke CW, Scanton MF. Dopamine agonists and pituitary tumour shrinkage. Endocrine Rev 1992:13:220-40.

122.Klibansky A, Deutsch PJ, Jameson JL, Ridgway EC, et al. Luteinizing hormone-secreting pituitary tumor: biosynthetic characterization and clinical studies. J Clin Endocrinol Metab 1987;64:536-42.

123. Berezin M, Olchovsky D. Pines A, et al. Reduction of follicle-stimulating hormone (FSH) secretion in FSH-producing pituitary adenoma by bromocriptine. J Clin Endocrinol Metab 1984;59:1220-2.

124. Ferone D, Lastoria S, Colao A, Varrella P, Cerbone $G$, Acampa $W$, et al Correlation of scintigraphic results using $123_{\text {--methoxybenzamide with hormone levels and }}$ tumor size response to quinagolide in patients with pituitary adenomas. J Clin Endocrinol Metab 1998;83:248-52

125. Hedner P, Valdemarsson S. Reduced size of a hormonally silent pituitary adenoma during treatment with $\mathrm{CV}$ 205-502, a new dopamine agonist mainly stimulating $D_{2}$ receptors. Neurosurgery 1989;25:948-50.

126. Kwekkboom DJ, Lamberts SWJ. Long-term treatment with dopamine agonist 126-CV 205-502 of patients with clinically non-functioning, gonadotroph, or a-subunit secreting pituitary adenoma. Clin Endocrinol (Oxf) 1992;36:171-7.

127. Colao A, Ferone D, Lastoria S, Cerbone $G$, et al. Hormone levels and tumour size response to quinagolide and cabergoline in patients with prolactin-secreting and clinically non-functioning pituitary adenomas: predictive value of pituitary scintigraphy with 123 -methoxybenzamide. Clin Endocrinol (Oxf) 2000:52:437-45.

128.Krenning EP, Kwekkeboom DJ, Bakker WH, Breeman WAP, et al. Somatostatin receptor scintigraphy with (In-DTPA-d-Phe_) and ([ I-Tyr_)-octreotide: the Rotterdam experience with more than 1000 patients. Eur J Nucl Med 1993:20:716-31.

129. Faglia G, Bazzoni N, Spada A. In vivo detection of somatostatin receptors in patients with functionless pituitary adenomas by means of a radioiodinated analog of somatostatin (( I)-SDZ 204-090). J Clin Endocrinol Metab 1991:73:850-6.

130.Plöckinger U, Bader M, Hopfenmuller W, Seager W, Quabbe HJ. Results of somatostatin receptor scintigraphy do not predict pituitary tumor volume and hormone response to octreotide therapy and do not correlate with tumor histology. Eur J Endocrinol 1997; 136:369-76.

131. Warnet A, Harris AG, Renard E, Martin D, James-Deidier $A$, Chaumet-Riffaud $P$ and the French multicenter octreotide study group. A prospective multicenter trial of octreotide in 24 patients with visual defects caused by nonfunctioning and gonadotropin-secreting pituitary adenomas. Neurosurgery 1997;41:786-97.

132. Greenman Y, Melmed S. Diagnosis and management of nonfunctioning pituitary tumors. Annu Rev Med 1996:47:95-106.

133.Snyder PJ. Gonadotroph adenomas. In: Melmed S, Editor. The Pituitary. Cambrigde:Blackwell Science, 1995: 559-75. 
134. Pompil A, Poggi M. Oppido PA, Raus L, et al. Lanreotide and cabergoline pre-operative therapy in non-functioning macroadenomas without visual impairement. Pituitary $2000: 3: 34$.

135. de Bruin TW, Kwekkerboom DJ, van't Verlaat JW. Reubi $\mathrm{JC}$, et al. Clinically non-functioning pituitary adenomas and octreotide response to long-term high-dose treatment, and studies in vitro. J Clin Endocrinol Metab 1992;75:1310-7.

136.McGrath GA, Gonçalves R, Udupa R, Grossmman Rl, Pavlou SN, Molitch ME. New technique for quantifica- tion of pituitary adenoma size: use in evaluating treatment of gonadotroph adenomas with a gonadotropinreleasing hormone antagonist. J Clin Endocrinol Metab 1993:76:1363-8.

\section{Endereço para correspondência:}

Lucio Vilar

Rua Clóvis Silveira Barros, 84/1202 - Boa Vista

50.050-270 Recife, PE 